Ferrata Storti Foundation

\title{
Dietary intake of heme iron is associated with ferritin and hemoglobin levels in Dutch blood donors: results from Donor InSight
}

Haematologica 2020

Volume 105(10):2400-2406

\section{Correspondence:}

KATJA VAN DEN HURK

k.vandenhurk@sanquin.nl

Received: June 13, 2019.

Accepted: November 12, 2019.

Pre-published: November 14, 2019.

doi:10.3324/haematol.2019.229450

(C)2020 Ferrata Storti Foundation

Material published in Haematologica is covered by copyright. All rights are reserved to the Ferrata Storti Foundation. Use of published material is allowed under the following terms and conditions:

https://creativecommons.org/licenses/by-nc/4.0/legalcode. Copies of published material are allowed for personal or internal use. Sharing published material for non-commercial purposes is subject to the following conditions:

https://creativecommons.org//icenses/by-nc/4.0/legalcode, sect. 3. Reproducing and sharing published material for commercial purposes is not allowed without permission in writing from the publisher.

\author{
Tiffany C. Timmer, ${ }^{1,2,3}$ Rosa de Groot, ${ }^{1,4}$ Judith J.M. Rijnhart, ${ }^{4}$ \\ Jeroen Lakerveld, ${ }^{4}$ Johannes Brug, ${ }^{5,6}$ Corine W.M. Perenboom, ${ }^{7}$ \\ A. Mireille Baart, ${ }^{7}$ Femmeke J. Prinsze,${ }^{1}$ Saurabh Zalpuri, ${ }^{1}$ \\ C. Ellen van der Schoot, ${ }^{3,8}$ Wim L.A.M. de Kort ${ }^{1,2}$ and Katja van den Hurk ${ }^{1}$
}

${ }^{1}$ Sanquin Research, Department of Donor Medicine Research - Donor Studies, Amsterdam; ${ }^{2}$ Amsterdam UMC, University of Amsterdam, Department of Public Health, Amsterdam Public Health, Amsterdam; ${ }^{3}$ Landsteiner Laboratory, Amsterdam UMC, University of Amsterdam, Amsterdam; ${ }^{4}$ Amsterdam UMC, Location VU University Medical Center, Department of Epidemiology and Biostatistics, Amsterdam Public Health Research Institute, Amsterdam; ${ }^{5}$ National Institute for Public Health and the Environment, Bilthoven; ${ }^{6}$ University of Amsterdam, Amsterdam School of Communication Research (ASCoR), Amsterdam; ${ }^{7}$ Wageningen University and Research, Division of Human Nutrition and Health, Wageningen and ${ }^{8}$ Sanquin Research, Department of Experimental Immunohematology, Amsterdam, the Netherlands

\section{ABSTRACT}

W Thole blood donors, especially frequently donating donors, have a risk of iron deficiency and low hemoglobin $(\mathrm{Hb})$ levels, which may affect their health and eligibility to donate. Lifestyle behaviors, such as dietary iron intake and physical activity, may influence iron stores and thereby $\mathrm{Hb}$ levels. We aimed to investigate whether dietary iron intake and questionnaire-based moderate-to-vigorous physical activity (MVPA) were associated with Hb levels, and whether ferritin levels mediated these associations. In Donor InSight-III, a Dutch cohort study of blood and plasma donors, data on heme and non-heme iron intake (mg/day), MVPA (10 minutes/day), Hb levels (mmol/L) and ferritin levels ( $\mu \mathrm{g} / \mathrm{L})$ were available in 2,323 donors (1,074 male). Donors with higher heme iron intakes [regression coefficients $(\beta)$ in men and women: 0.160 and 0.065 $\mathrm{mmol} / \mathrm{L}$ higher $\mathrm{Hb}$ per $1 \mathrm{mg}$ of heme iron, respectively] and lower nonheme iron intakes ( $\beta$ : -0.014 and -0.017 , respectively) had higher $\mathrm{Hb}$ levels, adjusted for relevant confounders. Ferritin levels mediated these associations [indirect effect ( $95 \%$ confidence interval) in men and women, respectively: $0.074(0.045 ; 0.111)$ and $0.061(0.030 ; 0.096)$ for heme and -0.003 $(-0.008 ; 0.001)$ and $-0.008(-0.013 ;-0.003)$ for non-heme]. MVPA was negatively associated with $\mathrm{Hb}$ levels in men only $(\beta$ : -0.005$)$, but not mediated by ferritin levels. In conclusion, higher heme and lower non-heme iron intake were associated with higher Hb levels in donors, via higher ferritin levels. This indicates that donors with high heme iron intake may be more capable of maintaining iron stores to recover $\mathrm{Hb}$ levels after blood donation.

\section{Introduction}

A whole blood donation results in the loss of approximately 225-250 mg of iron. ${ }^{1}$ Therefore, frequent whole blood donations may lead to iron depletion and a subsequent decline in hemoglobin $(\mathrm{Hb})$ levels. ${ }^{2,3}$ In order to ensure donor health and blood product quality, donor eligibility criteria are set. ${ }^{4}$ In many countries, including the Netherlands, minimum $\mathrm{Hb}$ levels are mandated at each donation: in the Netherlands these are $8.4 \mathrm{mmol} / \mathrm{L}(135 \mathrm{~g} / \mathrm{L})$ for men and $7.8 \mathrm{mmol} / \mathrm{L}(125 \mathrm{~g} / \mathrm{L})$ for women. A study among blood donors has shown that donors differ in $\mathrm{Hb}$ level recovery after blood donation, with some donors showing relatively stable $\mathrm{Hb}$ trajectories over time, while other donors show declining trajectories. ${ }^{5}$ This latter may 
be due to the fact that for those donors a donation interval of 56 days, which is the minimum interval in many countries including the Netherlands, is too short to restore $\mathrm{Hb}$ levels. ${ }^{2,6,7}$ Several factors, including sex, age, season and number of donations are established determinants of $\mathrm{Hb}$ levels. ${ }^{8-12}$ It may be speculated that differences in lifestyle behaviors between donors, such as dietary iron intake and physical activity, may influence Hb levels as well.

Iron homeostasis is tightly regulated and maintained by recycling iron from old erythrocytes, by replacing lost iron with dietary iron, and by mobilizing stored iron when necessary. ${ }^{1,13,14}$ In blood donors, dietary iron intake may be even more important in order to maintain iron homeostasis and thereby $\mathrm{Hb}$ levels given the iron loss associated with blood donation. A diet generally contains heme iron (present in animal foods) with high bioavailability (15$35 \%$ ) and non-heme iron (especially present in plantbased foods) with 1-20\% bioavailability. ${ }^{14,15}$ Heme iron generally constitutes only about $15 \%$ of the total dietary iron intake. ${ }^{14,15}$ Two previous studies among blood donors did not find associations between intake of iron-rich food items and iron stores or $\mathrm{Hb}$ levels, ${ }^{16,17}$ while one study among blood donors found mainly meat intake to be associated with iron stores. ${ }^{18}$ To our knowledge, it is unknown whether dietary heme and non-heme iron intake are positively associated with $\mathrm{Hb}$ levels and iron stores in blood donors. Physical activity may influence $\mathrm{Hb}$ levels as well. Available literature suggests two general hypotheses with regard to this relation. First, physical activity may decrease $\mathrm{Hb}$ levels through iron loss via sweat, urine, and the gastrointestinal tract, as well as by exercise-induced hemolysis or hemodilution. ${ }^{19-21}$ Second, physical activity may increase $\mathrm{Hb}$ levels as physical activity requires increased amounts of oxygen to be transported throughout the body by $\mathrm{Hb}^{22-24}$ The number of studies investigating the effect of physical activity on ferritin levels (i.e. a measure representing iron stores) $)^{14,25}$ are limited, particularly in blood donors, and the results of these studies are inconclusive. ${ }^{26-}$ 29

Insights into associations between lifestyle behaviors and $\mathrm{Hb}$ levels are valuable for blood supply organizations. Lifestyle behaviors can potentially be taken into account in order to prevent $\mathrm{Hb}$ deferrals, for example through tailored donation intervals or lifestyle advice. In addition, studying the mediating role of ferritin levels in the associations between lifestyle behaviors and $\mathrm{Hb}$ levels will help to gain insight into whether iron stores could indeed be the limiting or enabling factor that links lifestyle behavior to $\mathrm{Hb}$ level recovery after donation. In a Swiss study, donors who were low in $\mathrm{Hb}$ or ferritin levels could choose one or more of the three following strategies: (i) iron supplementation; (ii) extension of the donation interval; and/or (iii) suggestions of dietary changes. ${ }^{30}$ This study found that these measures contributed to an increase in $\mathrm{Hb}$ level. ${ }^{30}$ The Dutch Donor InSight-III (DIS-III) study provides both questionnaire-based and accelerometryderived data on physical activity, as well as data on both heme and non-heme iron intake using validated questionnaires. ${ }^{31}$ This, in combination with measurements of $\mathrm{Hb}$ and ferritin levels, provides a unique opportunity to study how lifestyle behaviors are related to $\mathrm{Hb}$ levels in blood donors. Hence, we investigated: (i) associations between dietary iron intake and physical activity with $\mathrm{Hb}$ levels and $\mathrm{Hb}$ trajectories; and (ii) to what extent these associations are mediated by ferritin levels. We hypothesized that a higher intake of heme iron, and to a lesser extent of non-heme iron, is associated with higher ferritin and $\mathrm{Hb}$ levels. Additionally, we hypothesized a potential positive association between MVPA and ferritin and $\mathrm{Hb}$ levels.

\section{Methods}

\section{Study population}

Data were collected as part of DIS-III (2015-2016), a cohort study among blood and plasma donors in the Netherlands. DIS-III aimed at gaining insight into donor characteristics, health and behavior. Details of DIS-III have been described elsewhere and information about $\mathrm{Hb}$ trajectories is available in the Online Supplementary Methods. ${ }^{32}$

Participants completed a general questionnaire and food frequency questionnaire (FFQ) one week prior to providing blood samples for DIS-III. Blood samples were either taken from the sampling pouch of a blood bag or, if not combined with a regular donation, through venipuncture. These blood samples were used to do a full blood count and to store samples to measure ferritin at a later moment (see Measurements section). A total of 2,552 (42\% response rate) donors provided blood samples and completed the general questionnaire. For the current analyses, donors with self-reported diagnosis of hemochromatosis $(n=6)$, who used iron supplements medication $(\mathrm{n}=221)$ and who were pregnant during DIS-III ( $n=5)$ were excluded ( $n=229,9 \%$ in total), resulting in 2,323 participants. The Medical Ethical Committee of the Academic Medical Center (AMC) in the Netherlands and Sanquin's Ethical Advisory Board approved DIS-III and all participants gave their written informed consent.

\section{Measurements}

Hemoglobin levels and erythrocyte parameters [red blood cell count (RBC), hematocrit, mean cell volume (MCV), mean cell hemoglobin $(\mathrm{MCH})$, mean cell hemoglobin concentration $(\mathrm{MCHC})$ and red cell distribution width (RDW)] were measured for DIS-III using a hematology analyzer (XT-2000, Sysmex, Kobe, Japan) in an EDTA whole blood sample within 24 hours (h) after blood donation. ${ }^{33}$ Collected lithium heparin tubes were centrifuged within $24 \mathrm{~h}$ after DIS-III blood collection and resulting plasma was subsequently stored at $-80^{\circ} \mathrm{C} .^{34}$ Ferritin levels were measured within a year after blood collection, using the stored plasma sample from lithium heparin tubes (Architect Ci8200, Abbott Laboratories, IL, USA). ${ }^{34}$

Dietary heme and non-heme iron intake (mg/day) were measured with a $\mathrm{FFO}^{31}$ adapted to assess iron intake. The FFO assessed usual dietary consumption in the past four weeks. Physical activity and sedentary behavior were questionnaire-based as well as accelerometry-derived. Questionnaire-based assessments were done by using the validated International Physical Activity Questionnaire - Short Form (IPAQ-SF). ${ }^{35,36}$ Sedentary behavior was checked for confounding (see Online Supplementary Methods). Time spent in moderate-to-vigorous physical activity (MVPA) and sedentary behavior was expressed in minutes/day. In a subset of DIS-III participants ( $n=654)$, these were also objectively measured with accelerometers (wGT3X-BT and GT3X Actigraph, Pensacola, FL, USA) and data were handled using Troiano (2008) cut-off points ${ }^{37}$ See Online Supplementary Methods for details on possible confounders.

\section{Statistical analysis}

Descriptive statistics are presented as mean \pm standard deviation (SD), or in case of a skewed distribution as median and interquartile range (IOR). Associations between lifestyle behaviors 
Table 1. Characteristics of the study population.

\begin{tabular}{|c|c|c|}
\hline & Males $(n=1,074)$ & Females $(n=1,249)$ \\
\hline Age at DIS-III, years & $51.1 \pm 13.0$ & $47.0 \pm 13.0$ \\
\hline $\mathrm{Hb}$ level, mmol/L & $9.3 \pm 0.6$ & $8.4 \pm 0.6$ \\
\hline $\mathrm{RBC}, \times 10^{4}$ & $497.1 \pm 36.2$ & $452.8 \pm 34.1$ \\
\hline Hct, $\%$ & $44.9 \pm 2.7$ & $41.2 \pm 2.9$ \\
\hline MCV, fL & $90.5 \pm 4.6$ & $91.2 \pm 4.8$ \\
\hline $\mathrm{MCH}, \mathrm{amol}$ & $1875.9 \pm 106.5$ & $1862.7 \pm 252.2$ \\
\hline $\mathrm{MCHC}, \mathrm{mmol} / \mathrm{L}$ & $20.7 \pm 0.6$ & $20.4 \pm 2.0$ \\
\hline RDW, \% & $13.6(13.1-14.2)$ & $13.6(13.1-14.4)$ \\
\hline \multicolumn{3}{|l|}{ Subgroup } \\
\hline Stable Hb trajectory & $232(22 \%)$ & $433(35 \%)$ \\
\hline Declining $\mathrm{Hb}$ trajectory & $468(44 \%)$ & $438(35 \%)$ \\
\hline Random sample & $374(35 \%)$ & $378(30 \%)$ \\
\hline Ferritin level, $\mu \mathrm{g} / \mathrm{L}$ & $56.8(31.2-95.5)$ & $35.9(19.3-59.3)$ \\
\hline Heme iron intake, mg/day & $1.1(0.8-1.5)$ & $0.9(0.6-1.2)$ \\
\hline Non-heme iron intake, mg/day & $9.7(7.9-11.7)$ & $7.9(6.4-9.5)$ \\
\hline MVPA (questionnaire), min/day & $64.3(31.8-139.6)$ & $51.4(26.1-107.7)$ \\
\hline MVPA (accelerometer), min/day & $32.4(19.9-49.3)$ & $26.7(17.3-40.3)$ \\
\hline Sedentary behavior (questionnaire), min/day & $480.0(300.0-720.0)$ & $420.0(265.0-615.0)$ \\
\hline Sedentary behavior (accelerometer), min/day & $575.3(509.6-632.3)$ & $532.7(485.9-580.6)$ \\
\hline Initial $\mathrm{Hb}$ level*, $\mathrm{mmol} / \mathrm{L}$ & $9.5 \pm 0.6$ & $8.5 \pm 0.6$ \\
\hline Number of donations in 2 years before DIS-III & $4(0-7)$ & $2(0-4)$ \\
\hline Donation interval, months & $6(3-25)$ & $9(5-35)$ \\
\hline \multicolumn{3}{|l|}{ Current smoker } \\
\hline Yes & $86(8 \%)$ & $94(8 \%)$ \\
\hline No & $917(85 \%)$ & $1,060(85 \%)$ \\
\hline
\end{tabular}

Menstruation in past 6 months

\begin{tabular}{llr} 
Yes & NA & $563(45 \%)$ \\
No & NA & $671(54 \%)$ \\
\hline
\end{tabular}

Continuous variables: mean \pm standard deviation or median (interquartile range) if skewed; dichotomous variables: n (\%); NA: not applicable; DIS-III: Donor InSight-III; Hb: hemoglobin; RBC: red blood cell count; Hct: hematocrit; MCV: mean cell volume; MCH: mean cell Hb; MCHC: mean cell Hb concentration; RDW: red cell distribution width; MVPA moderate-to-vigorous physical activity. Note: due to missing data, numbers might not add up to total for dichotomous variables. Percentages might not add up to 100 because of rounding. *First capillary $\mathrm{Hb}$ measurement available in the blood bank information system.

(heme/non-heme iron intake and questionnaire-based MVPA) and $\mathrm{Hb}$ levels, and mediation analyses of ferritin levels as mediator of this association were studied using multiple linear regression analyses. Complete case analyses were performed, and in case of non-linear associations with skewed variables, the dependent variables were log-transformed. All models were constructed for men and women separately and adjusted for relevant confounders (Online Supplementary Methods and Online Supplementary Table S1).

\section{Results}

A total of 1,074 males and 1,249 females were included with a mean (SD) age of 51.1 (13.0) and 47.0 (13.0) years, respectively (Table 1 ). In total, 1,016 males and 1,171 females provided information on heme and non-heme iron intake, 795 males and 962 females provided information on self-reported MVPA, and 313 males and 357 females had information on accelerometry-derived MVPA. Men had higher median ferritin and mean $\mathrm{Hb}$ levels than women: 56.8 versus $35.9 \mu \mathrm{g} / \mathrm{L}$ and 9.3 versus 8.4 $\mathrm{mmol} / \mathrm{L}$, respectively. Median heme and non-heme iron intake were higher in men than in women (heme: 1.1 vs. $0.9 \mathrm{mg} /$ day; non-heme: 9.7 vs. $7.9 \mathrm{mg} / \mathrm{day})$. Higher medians were seen for questionnaire-based compared with accelerometry-derived MVPA and these medians were higher in men compared with women (questionnaire: 64.3 vs. 51.4 minutes/day; accelerometer: 32.4 vs. 26.7 minutes/day). ${ }^{38,39}$ In total, 232 males and 433 females had a stable $\mathrm{Hb}$ trajectory and 468 males and 438 females had a declining $\mathrm{Hb}$ trajectory.

\section{Associations of lifestyle behaviors with hemoglobin and ferritin levels}

Associations of heme and non-heme iron intake, and MVPA with $\mathrm{Hb}$ levels are presented in Table 2. Age was found not to be an effect modifier. Adjustments were made for: (i) age, smoking, menstruation (in women only); (ii) number of donations in the previous two years, time since last donation; (iii) sedentary behavior, heme and non-heme iron intake or MVPA; and (iv) initial $\mathrm{Hb}$ levels. A higher intake of one mg of heme iron per day was associated with 0.160 and $0.065 \mathrm{mmol} / \mathrm{L}$ higher $\mathrm{Hb}$ levels in men and women, respectively. Higher intake of non-heme iron, however, was associated with slightly 
Table 2. Associations between lifestyle behaviors (heme and non-heme iron intake and moderate-to-vigorous physical activity (MVPA)] and hemoglobin $(\mathrm{Hb})$ levels.

\begin{tabular}{|c|c|c|c|c|c|c|}
\hline & $\begin{array}{l}\text { Independent } \\
\text { variable }\end{array}$ & $\begin{array}{c}\text { Crude model } \\
\boldsymbol{\beta}(95 \% \mathrm{CI})\end{array}$ & $\begin{array}{c}\text { Model } 1 \\
\beta \text { (95\% CI) }\end{array}$ & $\begin{array}{c}\text { Model } 2 \\
\beta(95 \% \text { CI) }\end{array}$ & $\begin{array}{c}\text { Model } 3 \\
\beta(95 \% \text { CI) }\end{array}$ & $\begin{array}{c}\text { Model } 4 \\
\beta(95 \% \text { CI) }\end{array}$ \\
\hline \multirow[t]{3}{*}{ M } & Heme & $0.125(0.057 ; 0.193)$ & $0.123(0.055 ; 0.191)$ & $0.126(0.058 ; 0.194)$ & $0.188(0.103 ; 0.272)$ & $0.160(0.083 ; 0.238)$ \\
\hline & Non-heme & $-0.016(-0.026 ;-0.007)$ & $-0.017(-0.026 ;-0.008)$ & $-0.017(-0.026 ;-0.008)$ & $-0.021(-0.033 ;-0.008)$ & $-0.014(-0.025 ;-0.003)$ \\
\hline & MVPA & $-0.005(-0.009 ;-0.002)$ & $-0.005(-0.009 ;-0.002)$ & $-0.005(-0.009 ;-0.001)$ & $-0.006(-0.009 ;-0.002)$ & $-0.005(-0.008 ;-0.001)$ \\
\hline \multirow[t]{3}{*}{$\mathrm{F}$} & Heme & $0.106(0.033 ; 0.178)$ & $0.102(0.030 ; 0.174)$ & $0.106(0.034 ; 0.178)$ & $0.093(0.005 ; 0.181)$ & $0.065(-0.018 ; 0.148)$ \\
\hline & Non-heme & $-0.020(-0.032 ;-0.008)$ & $-0.021(-0.033 ;-0.010)$ & $-0.022(-0.033 ;-0.010)$ & $-0.022(-0.036 ;-0.007)$ & $-0.017(-0.031 ;-0.003)$ \\
\hline & MVPA & $-0.000(-0.004 ; 0.004)$ & $-0.002(-0.006 ; 0.002)$ & $-0.002(-0.006 ; 0.002)$ & $-0.003(-0.007 ; 0.001)$ & $-0.003(-0.007 ; 0.001)$ \\
\hline
\end{tabular}

M: males; F: females; $\beta$ : regression coefficient, $95 \% \mathrm{CI}$ : $95 \%$ confidence interval; MVPA: moderate-to-vigorous physical activity in $10 \mathrm{minutes} /$ day; Hb: hemoglobin in mmol/L. Heme and non-heme iron in mg/day. Model 1: adjusted for age,smoking, and menstruation (women only). Model 2: additionally adjusted for number of donations in the 2 years before DIS-III and donation interval. Model 3: additionally adjusted for sedentary behavior and MVPA in models with heme and non-heme iron intake as independent variables or sedentary behavior, heme and non-heme iron intake in models with MVPA as independent variable. Model 4: additionally adjusted for initial Hb level. Over 10\% of participants excluded due to missing data in males model 3-4 for heme and non-heme iron intake, and models 1-4 for MVPA, and in females model 1-4 for heme and non-heme iron intake and MVPA.

Table 3. Associations between lifestyle behaviors [heme and non-heme iron intake and moderate-to-vigorous physical activity (MVPA)] and hemoglobin $(\mathrm{Hb})$ levels and mediation by ferritin levels.

\begin{tabular}{|c|c|c|c|c|c|c|c|}
\hline $\begin{array}{l}\text { Lifestyle } \\
\text { behaviors }\end{array}$ & Mediator & $\begin{array}{c}\text { Dependent } \\
\text { variable }\end{array}$ & $\begin{array}{c}\text { Total } \\
\text { effect } \\
\text { (c path) }{ }^{\dagger}\end{array}$ & $\begin{array}{c}\text { Effect } \\
\text { of lifestyle } \\
\text { behaviors } \\
\text { on ferritin levels } \\
\text { (a path) } \\
\text { LN }(\beta \text { (95\% CI)) }\end{array}$ & $\begin{array}{l}\text { Effect } \\
\text { of ferritin } \\
\text { levels on } \\
\text { Hb levels } \\
\text { (b path) } \\
\beta \text { (95\% Cl) }\end{array}$ & $\begin{array}{l}\text { Direct } \\
\text { effect } \\
\text { (c'path) }\end{array}$ & $\begin{array}{c}\text { Indirect } \\
\text { effect } \\
\text { (a path * b path) }\end{array}$ \\
\hline
\end{tabular}

$\mathrm{M}$

\begin{tabular}{|c|c|c|c|c|c|c|c|}
\hline Heme & Ferritin* & $\mathrm{Hb}$ levels & $0.160(0.083 ; 0.238)$ & $0.288(0.192 ; 0.383)$ & & $0.090(0.014 ; 0.165)$ & $0.074(0.045 ; 0.111)$ \\
\hline Non-heme & & & $-0.014(-0.025 ;-0.003)$ & $-0.012(-0.027 ; 0.002)$ & $0.256(0.198 ; 0.314)$ & $-0.011(-0.022 ;-0.000)$ & $-0.003(-0.008 ; 0.001)$ \\
\hline MVPA & & & $-0.005(-0.008 ;-0.001)$ & $-0.000(-0.005 ; 0.004)$ & & $-0.005(-0.009 ;-0.002)$ & $-0.000(-0.001 ; 0.001)$ \\
\hline \\
\hline Heme & Ferritin* & $\mathrm{Hb}$ levels & $0.065(-0.018 ; 0.148)$ & $0.222(0.115 ; 0.328)$ & & $0.002(-0.077 ; 0.080)$ & $0.061(0.030 ; 0.096)$ \\
\hline Non-heme & & & $-0.017(-0.031 ;-0.003)$ & $-0.028(-0.046 ;-0.010)$ & $0.276(0.225 ; 0.327)$ & $-0.010(-0.023 ; 0.004)$ & $-0.008(-0.013 ;-0.003)$ \\
\hline MVPA & & & $-0.003(-0.007 ; 0.001)$ & $0.001(-0.004 ; 0.006)$ & & $-0.003(-0.007 ; 0.000)$ & $0.000(-0.001 ; 0.002)$ \\
\hline
\end{tabular}

M: males; F: females; $\beta$ : regression coefficient, $95 \% \mathrm{CI}$ : $95 \%$ confidence interval; BCI: bootstrapped confidence interval; MVPA: moderate-to-vigorous physical activity in 10 minutes/day; heme and non-heme iron intake in $\mathrm{mg} /$ day, ferritin levels in $\mu \mathrm{g} / \mathrm{L} ; \mathrm{Hb}$ level in $\mathrm{mmol} / \mathrm{L}$. * Residuals of ferritin levels were not normally distributed and therefore log transformed; this table presents log transformed data. $†$ These results are identical to the results of model 4 in Table 2 .Total effect (c path): association between heme and non-heme iron intake or MVPA and $\mathrm{Hb}$ level; a path: association between heme and non-heme iron intake or MVPA and mediating variable ferritin levels; $b$ path:association between mediating variable ferritin levels and Hb level; direct effect (c' path): association between heme and non-heme iron intake or MVPA and Hb level adjusted for mediating variable ferritin levels; indirect effect: indirect effect of heme and non-heme iron intake or MVPA on Hb level through mediating variable ferritin levels. Adjusted for age, smoking, menstruation (in models with women only), number of donations, donation interval,sedentary behavior,MVPA in models with heme and non-heme iron intake as independent variables or heme and non-heme iron intake in models with MVPA as independent variable, and initial Hb level.

lower $\mathrm{Hb}$ levels in men and women $(-0.014$ and -0.017 $\mathrm{mmol} / \mathrm{L}$, respectively). Spending more time per day on MVPA was associated with lower $\mathrm{Hb}$ levels, but these results were only statistically significant in men $[\beta$ (95\% CI): -0.005 (-0.008 to -0.001$)$ ] (Table 2).

Both, heme and non-heme iron intake, showed positive associations with ferritin levels. Table 3 (a path) shows log transformed results, as ferritin levels were not normally distributed. Back-transformation of these results showed 1.334 and $1.249 \mathrm{mmol} / \mathrm{L}$ higher ferritin levels per mg higher heme iron intake in men and women, respectively. For non-heme iron intake, these values were 0.988 and 0.972 for males and females, respectively. MVPA showed no statistically significant association with ferritin levels in either men $[\beta(95 \% \mathrm{CI})$ : 1.000 (0.995 to 1.004$)$ ) nor women ( $\beta$ (95\% CI): 1.001 (0.996 to 1.006)]. Lifestyle behaviors and $\mathrm{Hb}$ trajectories showed similar, but less pronounced, associations as those with $\mathrm{Hb}$ levels as outcome (Online Supplementary Table S2).

\section{Mediation by ferritin levels}

Associations between dietary iron intake and $\mathrm{Hb}$ levels were mediated by ferritin levels (Table 3). In both men and women, higher intake of heme iron was significantly associated with higher ferritin levels, and higher ferritin levels with higher Hb levels [b path: $0.256(0.198 ; 0.314)$ in men and $0.276(0.225 ; 0.327)$ in women]. The association between heme iron intake was largely mediated by ferritin, showing indirect effects of 0.074 (0.045; 0.111) in men and $0.061(0.030 ; 0.096)$ in women. The direct, nonmediated effect of heme iron intake on $\mathrm{Hb}$ levels was only statistically significant in men. Higher intake of non-heme iron was associated with lower ferritin and $\mathrm{Hb}$ levels. The association between non-heme iron intake and $\mathrm{Hb}$ levels was also mediated by ferritin, but only significantly in women [indirect effect: $-0.003(-0.008 ; 0.001)$ in men and $-0.008(-0.013 ;-0.003)$ in women].

Ferritin levels did not mediate the association between MVPA and Hb levels (Table 3). MVPA was not associated with ferritin levels (Table 3, a path) and accordingly, the 
Table 4. Associations between erythrocyte parameters and lifestyle behaviors [heme and non-heme iron intake and moderate-to-vigorous physical activity (MVPA)].

\begin{tabular}{|c|c|c|c|c|c|c|}
\hline $\begin{array}{l}\text { Independent } \\
\text { variable }\end{array}$ & $\begin{array}{c}\mathrm{RBC} \\
\beta(95 \% \text { Cl) }\end{array}$ & $\begin{array}{c}\text { Het } \\
\beta(95 \% \text { CI) }\end{array}$ & $\begin{array}{c}\text { MCV } \\
\beta(95 \% \text { CI) }\end{array}$ & $\begin{array}{c}\text { MCH } \\
\beta(95 \% \text { Cl) }\end{array}$ & $\begin{array}{c}\text { МCHC } \\
\beta(95 \% \text { Cl) }\end{array}$ & $\begin{array}{c}\text { RDW* } \\
\text { LN } \beta(95 \% \text { CI) }\end{array}$ \\
\hline
\end{tabular}

$\mathrm{M}$

$\begin{array}{lcccccc}\text { Heme } & 4.242(-0.397 ; 8.881) & 0.681(0.330 ; 1.033) & 0.612(0.005 ; 1.220) & 16.284(1.833 ; 30.736) & 0.043(-0.036 ; 0.122) & -0.004(-0.014 ; 0.006) \\ \text { Non-heme } & -0.484(-1.166 ; 0.198) & -0.076(-0.128 ;-0.025) & -0.072(-0.162 ; 0.017) & -1.137(-3.260 ; 0.987) & 0.004(-0.008 ; 0.015) & -0.001(-0.002 ; 0.001) \\ \text { MVPA } & -0.248(-0.457 ;-0.040) & -0.023(-0.039 ;-0.007) & -0.002(-0.029 ; 0.025) & -0.094(-0.744 ; 0.556) & 0.000(-0.004 ; 0.003) & 0.000(-0.001 ; 0.000) \\ \text { F } & & & & & & \\ \text { Heme } & 4.600(-0.791 ; 9.991) & 0.465(0.022 ; 0.908) & 0.099(-0.624 ; 0.822) & 1.786(-14.487 ; 18.058)^{\dagger} & -0.019(-0.109 ; 0.071)^{\dagger} & 0.003(-0.010 ; 0.016) \\ \text { Non-heme } & -0.573(-1.477 ; 0.330) & -0.082(-0.156 ;-0.008) & -0.073(-0.194 ; 0.048) & -2.076(-4.799 ; 0.647)^{\dagger} & -0.005(-0.020 ; 0.010)^{\dagger} & -0.001(-0.003 ; 0.001) \\ \text { MVPA } & -0.083(-0.329 ; 0.163) & -0.016(-0.037 ; 0.004) & -0.021(-0.054 ; 0.012) & -0.236(-0.977 ; 0.506)^{\dagger} & 0.002(-0.002 ; 0.006)^{\dagger} & 0.000(-0.001 ; 0.000)\end{array}$

M: males; F: females; $\beta$ : regression coefficient, $95 \% \mathrm{CI}: 95 \%$ confidence interval; $\mathrm{MCH}$ : mean cell hemolgobin (Hb) in $\mu$ mol; MVPA: moderate-to-vigorous physical activity in 10 minutes/day; heme and non-heme iron intake in mg/day; RBC: red blood cell count in x104; Hct: hematocrit in \%; MCV: mean cell volume in fL; MCH: mean cell Hb in amol; MCHC: mean cell $\mathrm{Hb}$ concentration in mmol/L; RDW: red cell distribution width in \%; ferritin levels in $\mu \mathrm{g} / \mathrm{L}$. * Residuals of ferritin levels and RDW were not normally distributed and therefore log transformed; this table presents log transformed data. Adjusted for age, smoking, menstruation (in models with women only), number of donations, donation interval, sedentary behavior, MVPA in models with heme and non-heme iron intake as independent variables or heme and non-heme iron intake in models with MVPA as independent variable, and initial Hb. 'Results with outlier removed, without outlier removed: heme [-29.812 (-77.210 to 17.585)], non-heme [-0.534 (-8.474 to 7.407)] and MVPA [-0.864 (3.025 to 1.297$)]$ for $\mathrm{MCH}$ and heme $[-0.292(-0.688$ to 0.103$)]$, non-heme [0.009 (-0.058 to 0.075$)]$ and MVPA [-0.003 (-0.021 to 0.015$)]$ for MCHC.

indirect effects were close to zero. The direct effect ( $c^{\prime}$ path) of MVPA on $\mathrm{Hb}$ level was statistically significant in men only $[\beta(95 \% \mathrm{CI}):-0.005(-0.009$ to -0.002$)]$. With regard to $\mathrm{Hb}$ trajectories, a significant indirect effect was found for heme and non-heme iron intake in women only (0.094 (0.013; 0.203) for heme iron and -0.011 (-0.026; -0.002) for non-heme iron). Ferritin did not mediate the other associations between lifestyle behaviors and $\mathrm{Hb}$ trajectories (Online Supplementary Table S3).

\section{Sensitivity and post-hoc analyses}

Table 4 shows the results of post-hoc analyses on associations between lifestyle behaviors and erythrocyte parameters. Heme iron intake, non-heme iron intake and MVPA were mainly associated with hematocrit. In men, associations were also found between heme iron intake and $\mathrm{MCV}$ and $\mathrm{MCH}$, and between MVPA and RBC.

In sensitivity analyses in a subset of the study population with accelerometry-derived MVPA, the direct effect of MVPA on $\mathrm{Hb}$ levels in men was no longer statistically significant in any model (Online Supplementary Table S4).

Post-hoc analyses in which additional adjustments for phytate-rich and polyphenol-rich food items were made showed similar associations with heme iron intake $[0.145$ $(0.066 ; 0.225)$ and $0.079(-0.007 ; 0.165)$ in men and women, respectively], while associations with non-heme iron intake diminished $[\beta(95 \% \mathrm{CI}): 0.000(-0.018 ; 0.018)$ and 0.015 (-0.036; 0.006) in men and women, respectively].

\section{Discussion}

In this study among Dutch blood donors, we found that dietary iron intake was associated with $\mathrm{Hb}$ levels of blood donors via ferritin levels. Heme iron intake showed a positive and non-heme iron intake a negative association with $\mathrm{Hb}$ levels. To put this amount of iron into perspective, 1 $\mathrm{mg}$ higher heme iron intake, equivalent to 58 grams of prepared beef or 700 grams of prepared chicken filet, ${ }^{40}$ was associated with $0.160 \mathrm{mmol} / \mathrm{L}$ higher $\mathrm{Hb}$ levels in men. With regard to non-heme iron, $1 \mathrm{mg}$ higher non-heme iron intake, equivalent to 60 grams of cooked whole wheat pasta or 2.5 salty herring (187.5 grams), ${ }^{40}$ was associated with $-0.014 \mathrm{mmol} / \mathrm{L}$ lower Hb levels in men. A statistically significant, but rather small $(-0.015 \mathrm{mmol} / \mathrm{L}$ for 30 $\mathrm{min} /$ day MVPA in men), negative association between questionnaire-based but not accelerometry-derived physical activity and $\mathrm{Hb}$ levels was found in men only. This association was independent of ferritin levels. Results were independent of frequency of previous donations as we adjusted for number of donations in the 2 years before DIS-III and donation interval.

As hypothesized, a positive association was found between heme iron intake and $\mathrm{Hb}$ and ferritin levels. It seems that donors who consume more heme iron can restore their iron stores better, resulting in higher ferritin and $\mathrm{Hb}$ levels. Further analyses in which lifestyle behaviors were associated with erythrocyte parameters showed that heme iron intake increases the volume of blood that is occupied by red blood cells (higher Hct) and vice versa (lower Hct) for non-heme iron intake and MVPA. In men, higher heme iron intake was also associated with higher $\mathrm{MCV}$ and $\mathrm{MCH}$, indicating that, in men, in addition to a larger volume of red blood cells, these cells also contain more $\mathrm{Hb}$. Interestingly, higher intake of non-heme iron was associated with lower $\mathrm{Hb}$ levels, independent of heme iron intake. An explanation might be that with higher intake of non-heme iron, more phytate-rich and polyphenol-rich foods and beverages (e.g., legumes, grains and coffee) are consumed, preventing absorption of nonheme iron. ${ }^{41-43}$ Indeed, post-hoc analyses with additional adjustments for phytate-rich and polyphenol-rich food items (i.e., legumes, bread, pasta, cereals, nuts and coffee) diminished the negative associations between non-heme iron intake and $\mathrm{Hb}$ levels. More precise measurements of total phytate and polyphenol intake, rather than the consumption of food items, would enable more accurate adjustments for these substances. With regard to MVPA, the negative association with $\mathrm{Hb}$ levels may be due to exercise-induced hemolysis; however, this has mainly been found in studies investigating endurance athletes. ${ }^{17,19,44}$ In the additional analyses of MVPA with erythrocyte parameters, we did find that more MVPA was associated with lower numbers of erythrocytes. Another 
potential explanation could be hemodilution, caused by exercise-induced plasma volume expansion. ${ }^{20}$ This phenomenon is often seen in athletes and is also known as sports anemia. ${ }^{20,21}$ However, based on the results of this study, no firm conclusions on mechanisms behind the association of MVPA with $\mathrm{Hb}$ levels can be drawn. In contrast to our findings on associations with $\mathrm{Hb}$ levels, there was only one statistically significant association between lifestyle behaviors and $\mathrm{Hb}$ trajectories (Online Supplementary Table S2). An explanation could be the loss of power to detect an association due to the dichotomization of the $\mathrm{Hb}$ level measurements into $\mathrm{Hb}$ trajectories (stable/declining) and the lower number of participants with a known $\mathrm{Hb}$ trajectory. ${ }^{45}$

Our finding that iron intake was associated with $\mathrm{Hb}$ and ferritin levels is in contrast with previous studies conducted among blood donors. ${ }^{16,17}$ However, these previous studies assessed consumption of iron-containing food items. Since the majority of iron in food is consumed as nonheme iron, and we found this to be negatively associated with $\mathrm{Hb}$ levels, heme iron needs to be distinguished from non-heme iron in order to recognize the positive effect on $\mathrm{Hb}$ levels of heme iron intake. Research among a general population of Dutch adults supports our findings; they also found that heme iron intake was positively, and nonheme iron intake negatively associated with iron status. ${ }^{46}$ With regard to physical activity, our results are in agreement with another study among Danish blood donors that also found a negative association for questionnairebased physical activity (hours/week) with $\mathrm{Hb}$ levels in men only $[\beta(95 \% \mathrm{CI})$ of $-0.09(-0.11$ to -0.06$)$ for nonsmokers and $-0.11(-0.18$ to -0.05$)$ for smokers]. ${ }^{17}$

Strengths of this study include the large study population and the detailed assessment of lifestyle behaviors, erythrocyte parameters and ferritin levels. As the FFO enabled us to calculate both heme and non-heme iron intake rather than assessing total iron intake, we were able to show that there are important differences in the direction and magnitude of the associations between heme and non-heme iron intake and $\mathrm{Hb}$ levels. A limitation of the $\mathrm{FFQ}$, however, is that it does not measure when and in which combination food items are consumed. ${ }^{47}$ Another limitation of this study is the use of questionnaire-based MVPA, which is prone to social desirability and recall bias, and the validity is known to differ across respondents from different socio-economic strata, but it is also the most cost-effective way to measure physical activity in a large sample and enables differentiation between types of activity. ${ }^{39,48,49}$ We did, however, use a validated questionnaire, ${ }^{35,36}$ and were able to perform sensitivity analyses with accelerometry-derived data in a subgroup of the participants. Results were similar but not significant in the accelerometry sub-group, probably due to the smaller study population. Next, it could be argued that including menstruating women in the analyses could have altered associations between heme and non-heme iron intake and $\mathrm{Hb}$ levels in this subpopulation. However, analyses showed that menstrual status was not an effect modifier of the association between iron intake and $\mathrm{Hb}$ levels, indicating that the association between iron intake and $\mathrm{Hb}$ levels is similar for menstruating versus non-menstruating women. Last, analyses of this study were cross-sectional, and we are therefore unable to infer causation.

The results from this observational study do not implicate that blood donors will benefit from dietary advice. A review regarding solutions to iron deficiency in young women living in industrialized countries showed that dietary advice was not associated with an increase in $\mathrm{Hb}$ levels in two studies, but these studies showed conflicting results with regard to the effect of dietary advice on ferritin levels. ${ }^{50} \mathrm{~A}$ study among Swiss donors found that iron supplementation, extension of the donation interval, and/or suggestions of dietary changes resulted in a decrease in the prevalence of anemia and iron deficiency. ${ }^{30}$ However, this study was limited by the fact that donors were not randomized to one of the three interventions and no standardized information was handed out to the donor. ${ }^{30}$ Lastly, a study among blood donors conducted by our research group found that dietary advice did not reduce the risk of low-Hb deferral. ${ }^{51}$ Tailored donation intervals might be useful in preventing low $\mathrm{Hb}$ levels in blood donors ${ }^{3,6,7}$ however, the usefulness of dietary information in tailoring these intervals should first be investigated further.

In conclusion, blood donors with a higher intake of heme iron and lower intake of non-heme iron generally had higher $\mathrm{Hb}$ levels, and this was mediated by higher ferritin levels. In men, more time spent in MVPA was associated with lower $\mathrm{Hb}$ levels, independent of ferritin. Giving separate consideration to heme iron intake and non-heme iron intake may be useful in the prevention of low $\mathrm{Hb}$ levels in blood donors.

\section{Funding}

This work was supported by a Product and Process Development Grant (PPOC-14-028) from the Sanquin Blood Supply Foundation.

\section{Acknowledgments}

The authors would like to thank all participants and blood bank personnel for their contribution to the study. The authors also would like to thank J. van Rosmalen and K. Nasserinejad for fitting the growth mixture models and EMJ Huis in 't Veld for her contribution to the plan for analyses in an early stage.

\section{References}

1. O'Brien SF, Goldman M. Understanding iron depletion and overload in blood donors. ISBT Sci Ser. 2017;12(1):11-18.

2. Niittymaki P, Arvas M, Larjo A, et al. Retrospective analysis of capillary hemoglobin recovery in nearly 1200000 blood donor returns. Blood Adv. 2017;1(14):961967.

3. Schotten N, Pasker-de Jong PC, Moretti D, et al. The donation interval of 56 days requires extension to 180 days for whole blood donors to recover from changes in iron metabolism. Blood. 2016; 128(17):2185-2188.

4. Council of Europe. Guide to the preparation, use and quality assurance of blood components, European Committee (partial agreement) on Blood Transfusion (CD-PTS): Recommendation no. r(95) 15. 15 ed. Strasbourg: Council of Europe 2010.

5. Nasserinejad K, van Rosmalen J, van den
Hurk K, et al. Prevalence and determinants of declining versus stable hemoglobin levels in whole blood donors. Transfusion. 2015;55(8):1955-1963.

6. Di Angelantonio E, Thompson SG, Kaptoge S, et al. Efficiency and safety of varying the frequency of whole blood donation (INTERVAL): a randomised trial of 45000 donors. Lancet. 2017; 390(10110):2360-2371.

7. Baart AM, van den Hurk K, de Kort WLAM. Minimum donation intervals 
should be reconsidered to decrease low hemoglobin deferral in whole blood donors: an observational study. Transfusion. 2015;55(11):2641-2644.

8. Baart AM, de Kort WLAM, Atsma F, Moons KG, Vergouwe Y. Development and validation of a prediction model for low hemoglobin deferral in a large cohort of whole blood donors. Transfusion. 2012; 52(12):2559-2569.

9. Murphy WG. The sex difference in haemoglobin levels in adults - mechanisms, causes, and consequences. Blood Rev. 2014; 28(2):41-47.

10. Kelly A, Munan L. Haematologic profile of natural populations: red cell parameters. $\mathrm{Br}$ J Haematol. 1977;35(1):153-160.

11. Hoekstra T, Veldhuizen I, van Noord PA, de Kort WLAM. Seasonal influences on hemoglobin levels and deferral rates in wholeblood and plasma donors. Transfusion. 2007;47(5):895-900.

12. Kiss JE. Laboratory and genetic assessment of iron deficiency in blood donors. Clin Lab Med. 2015;35(1):73-91.

13. Ganz T. Systemic iron homeostasis. Physiol Rev. 2013;93(4):1721-1741.

14. Strain JJ, Cashman KD. Minerals and trace elements. Human nutrition: The Nutrition Society. 2009.

15. Cao C, Thomas CE, Insogna KL, O'Brien KO. Duodenal absorption and tissue utilization of dietary heme and nonheme iron differ in rats. J Nutr. 2014;144(11):17101717.

16. Cable RG, Glynn SA, Kiss JE, et al. Iron deficiency in blood donors: the REDS-II Donor Iron Status Evaluation (RISE) study. Transfusion. 2012;52(4):702-711.

17. Kotze SR, Pedersen OB, Petersen MS, et al. Predictors of hemoglobin in Danish blood donors: results from the Danish Blood Donor Study. Transfusion. 2015; 55(6):1303-1311.

18. Rigas AS, Sorensen CJ, Pedersen OB, et al. Predictors of iron levels in 14,737 Danish blood donors: results from the Danish Blood Donor Study. Transfusion. 2014;54(3 Pt 2):789-796.

19. Hinton PS. Iron and the endurance athlete. Appl Physiol Nutr Metab. 2014;39(9):10121018.

20. Eichner ER. Sports anemia, iron supplements, and blood doping. Med Sci Sports Exerc. 1992;24(9 Suppl):S315-S318.

21. Garvican-Lewis LA, Schumacher YO, Clark $\mathrm{SA}$, et al. Stage racing at altitude induces hemodilution despite an increase in hemoglobin mass. J Appl Physiol (1985). 2014;117(5):463-472

22. Otto JM, Montgomery HE, Richards T. Haemoglobin concentration and mass as determinants of exercise performance and of surgical outcome. Extrem Physiol Med.
2013;2(1):33-40

23. Gim MN, Choi JH. The effects of weekly exercise time on $\mathrm{VO} 2 \mathrm{max}$ and resting metabolic rate in normal adults. J Phys Ther Sci. 2016;28(4):1359-1363

24. Fogelholm M, Alopaeus K, Silvennoinen T, Teirila J. Factors affecting iron status in non-pregnant women from urban south Finland. Eur J Clin Nutr. 1993;47(8):567574.

25. Lynch $\mathrm{S}$. The rationale for selecting and standardizing iron status indicators. Geneva: World Health Organization; 2012.

26. Schumacher YO, Schmid A, Grathwohl D, Bultermann D, Berg A. Hematological indices and iron status in athletes of various sports and performances. Med Sci Sports Exerc. 2002;34(5):869-875.

27. Murray-Kolb LE, Beard JL, Joseph LJ, Davey SL, Evans WJ, Campbell WW. Resistance training affects iron status in older men and women. Int I Sport Nutr Exerc Metab. 2001;11(3):287-298.

28. Milman N, Kirchhoff M. Relationship between serum ferritin and risk factors for ischaemic heart disease in 2235 Danes aged 30-60 years. J Intern Med. 1999;245(5):423433.

29. Bourque SP, Pate RR, Branch JD. Twelve weeks of endurance exercise training does not affect iron status measures in women. Am Diet Assoc. 1997;97(10):1116-1121.

30. O'Meara A, Infanti L, Stebler C, et al. The value of routine ferritin measurement in blood donors. Transfusion. 2011;51(10):2183-2188

31. Streppel MT, de Vries JH, Meijboom S, et al. Relative validity of the food frequency questionnaire used to assess dietary intake in the Leiden Longevity Study. Nutr J. 2013;12:75

32. Timmer TC, de Groot R, Habets K, et al. Donor InSight: characteristics and representativeness of a Dutch cohort study on blood and plasma donors. Vox Sang. 2019;114(2):117-128

33. Hill VL, Simpson VZ, Higgins JM, et al. Evaluation of the Performance of the Sysmex XT-2000i Hematology Analyzer With Whole Bloods Stored at Room Temperature. Lab Med. 2009;40(12):709-718.

34. Abbott. Ferritin. 2010 [cited; Available from: http://www.ilexmedical.com/ files/PDF/Ferritin_ARC.pdf

35. Mader U, Martin BW, Schutz Y, Marti B. Validity of four short physical activity questionnaires in middle-aged persons. Med Sci Sports Exerc. 2006;38(7):12551266

36. Craig CL, Marshall AL, Sjostrom M, et al. International physical activity questionnaire: 12 -country reliability and validity. Med Sci Sports Exerc. 2003;35(8):13811395
37. Troiano RP, Berrigan D, Dodd KW, Masse LC, Tilert T, McDowell M. Physical Activity in the United States Measured by Accelerometer. Med Sci Sports Exerc. 2008; 40(1):181-188.

38. Sabia S, van Hees VT, Shipley MJ, et al. Association between questionnaire- and accelerometer-assessed physical activity: the role of sociodemographic factors. Am J Epidemiol. 2014;179(6):781-790.

39. Skender S, Ose J, Chang-Claude J, et al. Accelerometry and physical activity questionnaires - a systematic review. BMC Public Health. 2016;16:515

40. The Netherlands Nutrition Centre. IJzer Voedingscentrum Encyclopedie [cited 05 06-2019]; Available from: https://www. voedingscentrum.nl/encyclopedie/ ijzer.aspx

41. Conrad ME, Umbreit JN. Iron absorption and transport-an update. Am J Hematol. 2000;64(4):287-298.

42. Lim KH, Riddell LJ, Nowson CA, Booth AO, Szymlek-Gay EA. Iron and zinc nutrition in the economically-developed world a review. Nutrients. 2013;5(8):3184-3211.

43. Kim EY, Ham SK, Shigenaga MK, Han O Bioactive dietary polyphenolic compounds reduce nonheme iron transport across human intestinal cell monolayers. J Nutr. 2008:138(9):1647-1651.

44. Smith JA. Exercise, training and red blood cell turnover. Sports Med. 1995;19(1):9-31.

45. Altman DG, Royston P. The cost of dichotomising continuous variables. BMJ. 2006;332(7549):1080.

46. Brussaard JH, Brants HA, Bouman M Lowik MR. Iron intake and iron status among adults in the Netherlands. Eur J Clin Nutr. 1997;51 Suppl 3:S51-S58.

47. Ahmadi A, Enayatizadeh N, Akbarzadeh $\mathrm{M}$, Asadi S, Tabatabaee SH. Iron status in female athletes participating in team ballsports. Pak J Biol Sci. 2010;13(2):93-96.

48. Adams SA, Matthews CE, Ebbeling CB, et al. The effect of social desirability and social approval on self-reports of physical activity. Am J Epidemiol. 2005;161(4):389398.

49. Winckers AN, Mackenbach JD, Compernolle $S$, et al. Educational differences in the validity of self-reported physical activity. BMC Public Health. 2015; 15:1299.

50. Beck KL, Conlon CA, Kruger R, Coad J. Dietary determinants of and possible solutions to iron deficiency for young women living in industrialized countries: a review. Nutrients. 2014;6(9):3747-3776

51. Baart AM, van den Hurk K, de Kort WLAM, et al. Impact of risk-dependent interventions on low haemoglobin deferral rates in whole blood donors. Vox Sang. 2020;115(3):171-181. 